\title{
Lutein, zeaxanthin and meso-zeaxanthin content of eggs laid by hens supplemented with free and esterified xanthophylls
}

\author{
John M. Nolan ${ }^{1}$, Katherine A. Meagher ${ }^{1}$, Alan N. Howard ${ }^{2,3}$, Rachel Moran ${ }^{1}$, David I. Thurnham ${ }^{4}$ and \\ Stephen Beatty ${ }^{1}$ \\ ${ }^{1}$ School of Health Science, Macular Pigment Research Group, Vision Research Centre, Waterford Institute of Technology, Waterford, Republic of \\ Ireland \\ ${ }^{2}$ Howard Foundation, Cambridge, UK \\ ${ }^{3}$ Downing College, University of Cambridge, Cambridge, UK \\ ${ }^{4}$ Northern Ireland Centre for Food and Health (NICHE), University of Ulster, Coleraine, UK
}

(Received 5 June 2015 - Final revision received 1 October 2015 - Accepted 27 October 2015)

Journal of Nutritional Science (2016), vol. 5, e1, page 1 of 10

doi:10.1017/jns.2015.35

Abstract

The xanthophyll carotenoids lutein (L), zeaxanthin (Z) and meso-zeaxanthin (MZ) are found at the macula, the central part of the retina, where they are referred to as macular pigment (MP). MP is studied in human subjects because of its proven role in enhancing visual function and its putative role in protecting against age-related macular degeneration. These benefits are probably due to the antioxidant and short-wavelength filtering properties of MP. It is known that eggs are a dietary source of $\mathrm{L}$ and $\mathrm{Z}$. This experiment was designed to measure the egg yolk carotenoid response to hen supplementation with L, Z and MZ. A total of forty hens were used in the trial and were divided into eight groups of five hens. Each group was supplemented (with about $140 \mathrm{mg}$ active xanthophylls/ $\mathrm{kg}$ feed) with one of the following oil-based carotenoid formulations for 6 weeks: unesterified L (group 1); L diacetate (group 2); unesterified Z (group 3); Z diacetate (group 4); unesterified MZ (group 5); MZ diacetate (group 6); L-MZ (1:1) diacetate mixture (group 7); L-MZ diacetate (1:3) mixture (group 8). Yolk carotenoid content was analysed weekly (in four randomly selected eggs) by HPLC. We found that hens supplemented with $\mathrm{Z}$ diacetate and $\mathrm{MZ}$ diacetate produced eggs with significantly greater carotenoid concentrations than their free form counterparts. This finding potentially represents the development of a novel food, suitable to increase MP and its constituent carotenoids in serum.

Key words: Lutein: Zeaxanthin: Meso-zeaxanthin: Lutein diacetate: Meso-zeaxanthin diacetate: Zeaxanthin diacetate: Egg fortification: Hen supplementation

The xanthophyll carotenoids lutein (L), zeaxanthin $(\mathrm{Z})$ and meso-zeaxanthin $(\mathrm{MZ})$ are found at the macula ${ }^{(1)}$, the central part of the retina responsible for fine detail and central vision $^{(2)}$. At this specialised location, they are referred to as macular pigment (MP) and, via their short-wavelength (blue) light filtration ${ }^{(3)}$ and antioxidant properties ${ }^{(4)}$, protect against age-related macular degeneration $(\mathrm{AMD})^{(5)}$. In addition, MP augmentation in humans has been shown to improve visual function in the AMD (diseased) retina ${ }^{(6-8)}$ and in the nondiseased (healthy) retina ${ }^{(9)}$. Also, studies have shown that $\mathrm{L}$ and $\mathrm{Z}$ are found in the human brain ${ }^{(10,11)}$, and recent reports suggest a role for these xanthophylls in supporting brain health and cognitive function ${ }^{(1-13)}$. Of note, the majority of studies to date have demonstrated MP augmentation and consequential visual benefits using over-the-counter carotenoid supplement preparations. Of interest, however, nutrient-enriched

Abbreviations: CisZ, 13-cis-zeaxanthin; L, lutein; MP, macular pigment; MTBE, methyl tert-butyl ether; MZ, meso-zeaxanthin; Z, zeaxanthin.

* Corresponding author: Professor J. Nolan, email jmnolan@wit.ie

(C) The Author(s) 2016. This is an Open Access article, distributed under the terms of the Creative Commons Attribution- NonCommercialNoDerivatives licence (http://creativecommons.org/licenses/by-nc-nd/4.0/), which permits noncommercial re-use, distribution, and reproduction in any medium, provided the original work is unaltered and is properly cited. The written permission of Cambridge University Press must be obtained for commercial re-use or in order to create a derivative work. 
(functional) foods may offer an alternative to food supplements as can be seen, for example, with fatty acids (e.g. n-3 and $n-6)$, which are now available from enriched eggs and milk $^{(14,15)}$.

$\mathrm{L}$ and $\mathrm{Z}$ are present in a typically varied $\operatorname{diet}^{(16)}$, whereas $\mathrm{MZ}$ is only found in trace amounts in marine-sourced foods, such as salmon, trout and sardines ${ }^{(17,18)}$. Despite the differing amounts of $\mathrm{L}, \mathrm{Z}$ and $\mathrm{MZ}$ found in foods, it is interesting to note that the ratio of these xanthophylls in the human retina is 1:1:1 (MZ:Z:L), suggesting a unique role for each of these carotenoids at this target tissue. Foods such as kale, spinach and maize contain high amounts of $\mathrm{L}$ and $\mathrm{Z}$, rendering such foods important sources of these carotenoids. However, the complex cellular structure of these higher plants impedes the release of the chromoplast-bound carotenoids ${ }^{(19)}$. It is for this reason that the bioaccessibility and bioavailability of these compounds need to be enhanced in order to increase their concentrations in serum. This can be achieved by optimising the mode of food preparation; for example, chopping, maceration, cooking of the plant tissue in question, and incorporation of oil when eaten ${ }^{(20,21)}$.

Of interest, although hen eggs contain lesser concentrations of $\mathrm{L}$ and $\mathrm{Z}$ than some leafy greens (e.g. spinach or kale) ${ }^{(16)}$, the high lipid content of the egg facilitates gastrointestinal digestion and absorption, and enhances the bioavailability of the carotenoids present in the yolk, making eggs a good source of these nutrients ${ }^{(22)}$. As a consequence, greater serum carotenoid responses have been observed following supplementation with egg yolk when compared with dietary fortification with spinach/kale extracts and even when compared with oilbased supplement preparations in human clinical trials ${ }^{(23)}$. Also, in that same study by Chung et al. ${ }^{(23)}$, it was reported that L bioavailability was comparable between free $\mathrm{L}$ and $\mathrm{L}$ esters.

Hen eggs are consumed as part of a typical healthy diet and are produced on an industrial scale to meet the high demand of egg and egg-based products on the market. A golden-yellow egg yolk is sought-after ${ }^{(24)}$, and the carotenoids L, Z and MZ are already added to hen feed (e.g. Industrial Orgánica) in order to enhance the cosmetic appearance and commercial value of the egg yolk, i.e. the increased carotenoid pigment gives rise to a richer yolk colouration. Also, it is possible that carotenoid-enriched eggs will offer advantages over standard eggs in terms of increasing MP levels, with consequential benefits for vision and cognitive function. It is known that, in general, supplementation with carotenoids results in increases in serum and retinal concentrations of the carotenoids. This has been demonstrated with carotenoid-rich foods, such as eggs ${ }^{(25,26)}$, and with carotenoid supplements containing L, Z and $\mathrm{MZ}(6,9,27,28)$

However, it is not known if the response of hens to esterified carotenoids differs with respect to their egg yolk carotenoid concentration, when compared with carotenoids in their free form. In 2002, Bowen et al. reported higher bioavailability in humans from a L ester formulation, when compared with the free form $(61 \%$ more bioavailable; $P<0.05)^{(29)}$. In 2009, Wu et al. reported that L bioavailability, measured in hen plasma, from free $\mathrm{L}$ and esterified $\mathrm{L}$ supplements was comparable ${ }^{(30)}$. However, their experiment did not analyse the impact of supplementation in the eggs of the hens supplemented with the esterified and free L supplements. Of note, the present study is the first study to compare $\mathrm{L}, \mathrm{Z}$ and $\mathrm{MZ}$ response in eggs of hens supplemented with free and esterified L, Z and MZ. On one hand, the free form of the carotenoids may offer advantages over the esterified carotenoids as they are readily available for absorption from the gut into the bloodstream, whereas esterified carotenoids need to undergo enzyme-catalysed hydrolysis, and there is little known about the digestion, absorption and metabolism of the esterified carotenoids. On the other hand, the esterified carotenoids may offer advantages over the free-form carotenoids because esterified carotenoids are known to be more stable than the free-form carotenoids, and are not degraded, to the same degree, by factors such as light and heat. Overall, knowledge in this area is limited and the present study is designed to address some of these important questions.

The present trial, known as the Egg Xanthophyll Intervention Trial (EXIT), was designed to measure egg yolk carotenoid response to hen supplementation with $\mathrm{L}, \mathrm{Z}$, and $\mathrm{MZ}$ in their free and esterified forms, including testing mixtures of esterified L and MZ on egg yolk carotenoid response.

\section{Methods}

\section{Housing and feed conditions}

The experimental methods implemented in this study conformed to Directive 2010/63/EU of the European Parliament and Council (22 September 2010) on the protection of animals used for scientific purposes. This study was reviewed and approved by the Ethics Committee of the Waterford Institute of Technology, Waterford, Republic of Ireland.

This hen supplementation trial was housed in a purposebuilt barn $(28 \times 12$ feet; $8.5 \times 3.7 \mathrm{~m})$ on a farm, which was quality assured by the Food Safety Authority of Ireland (Bord Bia), and which complied with all health standards prescribed by Bord Bia, including Salmonella testing. The hens were housed in large indoor pens to allow free movement. Inside the barn there were eight pens, which measured 8 feet deep $\times 4$ feet wide $(2.4 \mathrm{~m}$ deep $\times 1.2 \mathrm{~m}$ wide $)$ with can feeders and overhead nipple drinkers (ad libitum). Plastic slats were used for manure, in that the hens stood on them and the manure fell down between the slats (there was no litter material used to avoid contamination from the manure). The temperature of the bird house was approximately $18^{\circ} \mathrm{C}$. A light program of $15 \mathrm{~h}$ light per $\mathrm{d}$ was used in this trial, consistent with the standard practice of the hen farm.

The hens were of the Goldline variety, known to be excellent egg layers, and were all approximately 40 weeks of age at the start of the trial. All the hens were purchased from a local farmer, and were vetted prior to the commencement of the trial to ensure that the hens used in the trial were healthy. Their diet consisted of a standard commercially available 'crumbled grain' feed (High Performance Layers Mash, 
Southern Mills). This crumbled grain was selected over a pelleted feed due to its suitability for mixing with the oil-based carotenoid supplement. A 'carotenoid-free' feed was initially considered, but this concept was discarded in order to keep the trial conditions similar to those of typical egg production. The hens had an adaptation period of 1 week in the barn, where they were fed a standard diet containing the following ingredients: wheat meal; soya (bean) meal; maize; calcium carbonate (lime grit); distillers dried grains; barley; rapeseed meal; sunflower seed meal; mono-dicalcium phosphate; sodium chloride; animal fat; sodium bicarbonate. The composition of the nutrients was as follows: crude protein $16.0 \%$; crude oils and fats $2.7 \%$; Ca $3.80 \%$; Na $0.17 \%$; crude fibre $4.2 \%$; crude ash $12.6 \%$; lysine $0.68 \%$; P 0.56 $\%$; methionine $0.32 \%$.

\section{Hen intervention groups and feed supplements}

The forty hens involved in the trial were divided into eight groups of five hens and each group was supplemented with one of the following oil-based carotenoid formulations: unesterified L (group 1); L diacetate (group 2); unesterified Z (group 3); Z diacetate (group 4); unesterified MZ (group 5); MZ diacetate (group 6); L-MZ (1:1) diacetate mixture (group 7); L-MZ diacetate (1:3) mixture (group 8).The free carotenoids and their diacetates are presented in Fig. 1. The two intervention 'mixture' groups each comprised a mixture of L and MZ diacetates, as follows: group 7 in a L:MZ ratio of 1:1 and group 8 in a L:MZ ratio of 1:3, prepared in-house. The trial supplements were supplied by Industrial Orgánica and generally recognized as safe-approved by the Food and Drug Administration (lutein and zeaxanthin $\left(3 \mathrm{R}, 3^{\prime} \mathrm{R}\right)$ mixture: GRN 00029; lutein diacetate: GRN 000432; meso-zeaxanthin: GRN 000481). The supplements consisted of the carotenoid of interest (e.g. $\mathrm{Z}$ is the carotenoid of interest in groups 3 and 4), henceforth referred to as the 'target carotenoid', suspended in maize oil, in a declared concentration of approximately $20 \mathrm{~g} / \mathrm{kg}$. Vitamin E (DL- $\alpha$-tocopheryl acetate; $5 \mathrm{~g} / \mathrm{kg}$ ) was also included in the formulations as a preservative due to its strong antioxidant activity. These supplements were analysed in our laboratory after hydrolysis in order to quantify the specific $\mathrm{L}, \mathrm{Z}$ and $\mathrm{MZ}$ content in their free form, to determine the amount of feed concentrate to add to the feed mix and produce $140 \mathrm{mg} / \mathrm{kg}$. The resulting concentrations and the declared label content of the supplements are presented in Table 1.

\section{Hen feed mixing}

The carotenoid concentration of each of the six supplements was determined and was controlled in order to achieve a uniform dosage of $140 \mathrm{mg} / \mathrm{kg}$ ( $\mathrm{mg}$ of active carotenoid per $\mathrm{kg}$ of hen feed) across all intervention groups. Since the supplement was added to the feed via $100 \mathrm{ml}$ syringes, and given that the supplements had differing densities, the required quantity of the supplements to be added directly to the feed was converted to volume (ml) using the measured densities provided on the supplement labels and the measured concentrations of xanthophylls as obtained by HPLC. In the case of the mixture groups, the overall dosage was $140 \mathrm{mg} / \mathrm{kg}$ (i.e. 1:1 mixture contained $70 \mathrm{mg} / \mathrm{kg}$ of $\mathrm{L}$ and $70 \mathrm{mg} / \mathrm{kg}$ of MZ). Since some $\mathrm{L}$ was detected in the MZ supplement and vice versa, we included the amounts in our calculations.

The hen feed for all eight groups was prepared on a Wednesday, fortnightly. Each $14 \mathrm{~kg}$ batch of feed mixed provided 2 weeks' rations per group. The feed was mixed according to a predetermined mix-and-wash protocol to prevent cross-contamination between intervention groups. A planetary mixer (Gastrorag B40A; Commercial Refrigeration) set at medium speed and a $100 \mathrm{ml}$ syringe was used to incorporate the supplement. The feed and supplement were mixed for $10 \mathrm{~min}$ to ensure that a homogeneous mixture was produced, which was indicated by the uniform golden colour of the feed. The feed was then divided into $1 \mathrm{~kg}$ portions (a daily portion per group of five hens), vacuum-packed (CC771 Buffalo Vacuum packer) and stored at $-20^{\circ} \mathrm{C}$. A daily portion was provided to the hens in the morning and the feed remnants discarded the next morning to help reduce degradation of the carotenoids in the feed while it was exposed to air.

\section{Sample collection and storage}

Egg samples were collected at baseline (before the introduction of experimental diet) and on a weekly basis for a period of 6 weeks thereafter. A sample of four eggs was taken from each of the eight intervention groups at each visit. These eggs were taken from the batch of eggs laid on the day of collection. These egg samples were placed in designated 'group' trays and transported to the laboratory facility to undergo the yolk sample preparation step (described below) that day.

\section{Analytical methods}

The following analytical methodologies took place under amber light conditions (eW Blast Powercore BCP473; Philips Electronics Ireland Ltd), and in a temperaturecontrolled environment $\left(15-19^{\circ} \mathrm{C}\right)$ to minimise carotenoid degradation.

\section{Hen feed supplement analysis}

The six hen feed supplements used in the trial were sealed in individual $5 \mathrm{~kg}$ containers upon delivery to the laboratory. These containers were placed in a $40^{\circ} \mathrm{C}$ water bath for $1 \mathrm{~h}$ (in accordance with label instruction), then subjected to mixing by inversion prior to breaking the seal. Quantities of $50 \mathrm{mg}$ were taken in triplicate from each supplement container and each sample was dissolved in $50 \mathrm{ml}$ of acetone. A volume of $1 \mathrm{ml}$ of the resulting solution was removed to a $25 \mathrm{ml}$ volumetric flask and also made up in acetone. Then $0.5 \mathrm{ml}$ of this working solution was transferred to a clear $1.5 \mathrm{ml}$ Eppendorf tube, to which was added $0.1 \mathrm{ml}$ of internal standard (echinenone, $0.4 \mathrm{mg} / 10 \mathrm{ml}$ ethanol) and $0.5 \mathrm{ml}$ of aqueous $\mathrm{KOH}(25 \mathrm{~g} / 100 \mathrm{ml}$ water). The samples were allowed to saponify for $1 \mathrm{~h}$ at $45^{\circ} \mathrm{C}$ in a shaking incubator (Stuart 


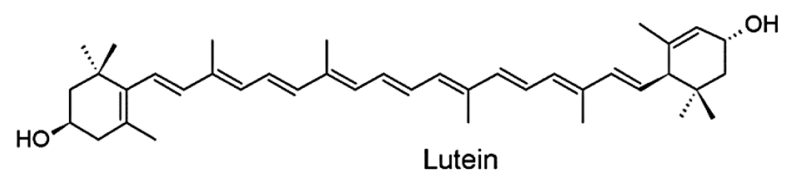<smiles>CC(=O)OC1CC(C)=C(/C=C/C(C)=C/C=C/C([18O])=C/C=C/C=C(C)/C=C/C=C(C)/C=C/C2=C(C)CC(OC(C)=O)C(C)C2)C(C)(C)C1</smiles><smiles>CC1=C(/C=C/C=C(C)/C=C/C=C(C)/C=C/C=C(C)/C=C/C=C(C)/C=C/C2=C(C)CC(O)CC2(C)C)C(C)CC(O)C1</smiles>

Zeaxanthin<smiles>CC(=O)OC1CC(C)=C(/C=C/C(C)=C/C=C/C(C)=C/C=C/C=C(C)/C=C/C=C(C)/C=C/C2=C(C)CC(OC(C)=O)C(C)C2)C(C)(C)C1</smiles>

Zeaxanthin diacetate

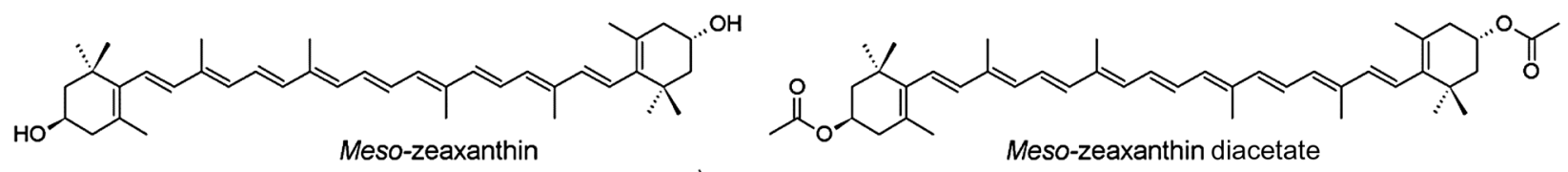
Meso-zeaxanthin

Meso-zeaxanthin diacetate

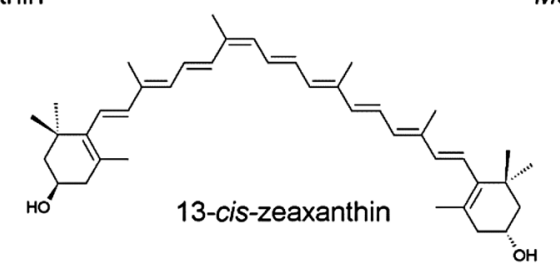

Fig. 1. Chemical structures of the free-form carotenoids and their diacetates.

Orbital Incubator, SI500; Carl Stuart Ltd) and then allowed to cool to room temperature prior to extraction. A quantity of $0 \cdot 5$ ml of hexane containing $0.1 \%$ butylated hydroxytoluene (BHT; $100 \mathrm{mg} / \mathrm{l}$ ) was added as the extraction solvent to each sample, and the mixture was vortexed (VortexGenie; Carl Stuart Ltd) for 2 min and centrifuged with an AccuSpin Micro 17 (Fisher Scientific) at $400 \mathrm{~g}$ for $5 \mathrm{~min}$. Then $0.5 \mathrm{ml}$ of the yellow upper layer was transferred to an amber $1.5 \mathrm{ml}$ Eppendorf tube and the liquid extraction was repeated. The two extracts were combined and dried using a vacuum solvent concentrator (MiVac, GeneVac; Mason Technologies). The samples were immediately reconstituted in $0.2 \mathrm{ml}(0.1 \mathrm{ml}$ injection volume) of mobile phase (see assay 1) for HPLC analysis.

\section{Egg yolk preparation}

Egg yolks were individually weighed and also colour graded using the DSM Colour fan. The yolks were thoroughly mixed with PBS (0.01 $\mathrm{M}, \mathrm{pH} 7.4)$ and made up to $50 \mathrm{ml}$ in a volumetric flask. Then $3 \mathrm{ml}$ of each suspension was transferred to two clear $1.5 \mathrm{ml}$ Eppendorf tubes and stored at $-80^{\circ} \mathrm{C}$ until analysis.

\section{Yolk carotenoid extraction}

Four eggs from each group were analysed for carotenoid content, and each individual egg yolk sample was analysed without replication. The egg yolk suspension $(0.1 \mathrm{ml})$ was mixed with $0.15 \mathrm{ml}$ aqueous $\mathrm{KOH}(25 \mathrm{~g} / 100 \mathrm{ml}$ water $), 0.15 \mathrm{ml}$ absolute ethanol (containing BHT, $500 \mathrm{mg} / \mathrm{l}$ ) and $0.1 \mathrm{ml}$ echinenone (internal standard, $0.4 \mathrm{mg} / 10 \mathrm{ml}$ ethanol) in a clear $1.5 \mathrm{ml}$ Eppendorf tube and incubated at $45^{\circ} \mathrm{C}$ for $45 \mathrm{~min}$ in a shaking incubator (Stuart Orbital Incubator, SI500; Carl Stuart Ltd). The samples were then cooled and vortexed vigorously (VortexGenie; Carl Stuart Ltd) with $0.5 \mathrm{ml}$ of a 1:1 mixture of methyl tert-butyl ether (MTBE) and hexane and centrifuged

Table 1. Carotenoid content of each hen feed supplement preparation (Mean values and standard deviations)

\begin{tabular}{|c|c|c|c|c|c|c|c|c|c|c|c|}
\hline \multirow[b]{3}{*}{ Supplement } & \multirow[b]{3}{*}{ Density* } & \multicolumn{8}{|c|}{ Measured carotenoid content $\dagger$} & \multicolumn{2}{|c|}{$\begin{array}{l}\text { Declared carotenoid } \\
\text { contentł }\end{array}$} \\
\hline & & \multicolumn{2}{|c|}{ L (g/kg) } & \multicolumn{2}{|c|}{$\mathrm{Z}(\mathrm{g} / \mathrm{kg})$} & \multicolumn{2}{|c|}{$\mathrm{MZ}(\mathrm{g} / \mathrm{kg})$} & \multicolumn{2}{|c|}{$\mathrm{TZ}(\mathrm{g} / \mathrm{kg})$} & \multirow[b]{2}{*}{$\mathrm{L}(\mathrm{g} / \mathrm{kg})$} & \multirow[b]{2}{*}{$\mathrm{TZ}(\mathrm{g} / \mathrm{kg}) \S$} \\
\hline & & Mean & SD & Mean & SD & Mean & SD & Mean & SD & & \\
\hline MZ (free) & 0.92 & 14.65 & 1.49 & 4.98 & 0.19 & 36.60 & 4.58 & 41.58 & 4.77 & 11.59 & 24.37 \\
\hline Z (free) & 0.92 & $5 \cdot 68$ & 0.03 & 42.02 & 2.47 & 0.00 & 0.00 & 42.02 & $2 \cdot 47$ & 3.48 & 29.65 \\
\hline L (free) & 0.91 & $37 \cdot 45$ & 0.33 & 2.75 & 0.05 & 0.31 & 0.05 & 3.06 & 0.09 & $24 \cdot 77$ & 2.62 \\
\hline MZ diacetate & 0.92 & 2.99 & 0.46 & 2.25 & 0.33 & $25 \cdot 81$ & 3.12 & 28.06 & 3.46 & 4.66 & 25.46 \\
\hline Z diacetate & 0.92 & 1.95 & 0.28 & $16 \cdot 82$ & 0.89 & 0.00 & 0.00 & $16 \cdot 82$ & 0.89 & 3.45 & 23.78 \\
\hline L diacetate & 0.95 & 23.95 & 1.88 & 1.28 & 0.04 & 2.39 & 0.36 & 3.67 & 0.40 & $20 \cdot 54$ & 3.6 \\
\hline
\end{tabular}

L, lutein; Z, zeaxanthin; MZ, meso-zeaxanthin; TZ, total zeaxanthin (mixture of MZ and Z).

* Density refers to the density of the liquid supplement at room temperature.

† Measured carotenoid content refers to the carotenoid concentrations obtained by supplement analysis after hydrolysis, performed in-house; samples were analysed in triplicate.

$\ddagger$ Declared carotenoid content refers to the label-declared carotenoid concentrations given by the supplement supplier; the $\mathrm{g} / \mathrm{kg}$ unit refers to $\mathrm{g}$ active (carotenoid) per kg oil.

$\S \mathrm{MZ}$ and $\mathrm{Z}$ content was given as a combined (TZ) content on the supplement label. 
in an AccuSpin Micro 17 (Fisher Scientific) for $5 \mathrm{~min}$ at $400 \mathrm{~g}$ to separate the organic and aqueous layers. Then $0.4 \mathrm{ml}$ of the upper organic layer was transferred to an amber $1.5 \mathrm{ml}$ Eppendorf tube and the residue was re-extracted with $0.5 \mathrm{ml}$ of the MTBE-hexane mixture. After centrifuging, $0.4 \mathrm{ml}$ of the upper layer was removed and combined with the first extract, then dried using a vacuum solvent concentrator (MiVac, GeneVac; Mason Technologies). The samples were stored under $-80^{\circ} \mathrm{C}$ conditions until the time of HPLC analysis, which was completed within $1 \mathrm{~d}$ of extraction. Samples were reconstituted in $0.2 \mathrm{ml}$ of mobile phase A (see assay 1) and $0.05 \mathrm{ml}$ was used as the injection volume ${ }^{(31)}$.

\section{HPLC (assay 1)}

The Agilent 1260 Infinity HPLC system (Agilent Technologies) was used for assay 1 analysis, and was equipped with the following: binary pump with an adjacent degasser; a diode array detector; temperature-controlled autosampler; temperature-controlled column compartment; and fraction collector.

All extracted samples (both hen feed supplement and yolk samples) were first run on assay 1 , a reverse-phase method capable of separating the main carotenoid structures, i.e. xanthophylls and carotenes, as well as trans- and cis-carotenoid structures (using a method modified from Yeum et al. ${ }^{(31)}$ ). All-trans $\mathrm{L}$ and total all-trans $\mathrm{Z}$ (a mixture of the stereoisomers $\mathrm{Z}$ and MZ) were separated and quantified using this technique. A YMC C30 column $(250 \times 4.6 \mathrm{~mm}, 3 \mu \mathrm{m})$ with a $10 \times 4 \mathrm{~mm}$, $3 \mu \mathrm{m}$ YMC Guard Cartridge (guard and column; Apex Scientific) maintained at $15^{\circ} \mathrm{C}$ was used for this analysis. The gradient method used a 83:15:2 mixture of methanol (MeOH)-MTBE-water as solvent A, and a 8:90:2 mixture of $\mathrm{MeOH}-\mathrm{MTBE}-$ water as solvent $\mathrm{B}$. The initial isocratic settings were $90 \% \mathrm{~A}$ and $10 \% \mathrm{~B}$ for $17 \mathrm{~min}$, followed by a linear increase to $60 \% \mathrm{~B}$ between 17 and $25 \mathrm{~min}$. The system was then allowed to return to the initial settings over $2 \mathrm{~min}$ prior to the next injection. A consistent flow rate of $1 \mathrm{ml} / \mathrm{min}$ was used throughout the analyses. L typically eluted at approximately $7 \mathrm{~min}$ and total $\mathrm{Z}$ at approximately $8.7 \mathrm{~min}$. The total $\mathrm{Z}$ peak was automatically recognised and collected in Eppendorf tubes by the system's fraction collector, then dried down using the solvent concentrator (MiVac, GeneVac; Mason Technologies). The collected total Z samples were stored under $-80^{\circ} \mathrm{C}$ until analysis on assay 2 .

\section{HPLC (assay 2)}

The Agilent 1200 HPLC system was used for assay 2 analysis, and was equipped with the following: quaternary pump with an adjacent degasser; a diode array detector; temperaturecontrolled autosampler; temperature-controlled column compartment. Assay 2 is a normal-phase chiral method incorporating a Daicel AI-3 CHIRALPAK $250 \times 4.6 \mathrm{~mm}, 3 \mu \mathrm{m}$ column with a $0.5 \mu \mathrm{m}$ in-line filter used for the chiral separation of $\mathrm{Z}$ and MZ. All the collected total $\mathrm{Z}$ fractions were analysed for MZ. This gradient method used $n$-hexane as solvent A and iso-propanol as solvent B with a flow rate of
$0 \cdot 8 \mathrm{ml} / \mathrm{min}$. The initial settings were 95:5 hexane-isopropanol, which was isocratic for the first $5 \mathrm{~min}$, then developed a slow linear gradient to $10 \%$ isopropanol over the next $20 \mathrm{~min}$. The system then plateaued at $15 \%$ isopropanol for $5 \mathrm{~min}$, before returning to the initial settings for $4 \mathrm{~min}$ in preparation for the next injection. MZ and $Z$ elute at 27.7 and $28.5 \mathrm{~min}$, respectively. The MZ: $Z$ ratio was achieved using their associated peak areas in assay 2 , and was applied to the concentration of total $\mathrm{Z}$ obtained in assay 1 in order to individually quantify MZ and Z. This is known as the method of proportions technique ${ }^{(32)}$.

\section{Statistical analysis}

The statistical packages SPSS (SPSS version 19; IBM version 21; SPSS), were used for data analysis. Between-group differences for yolk carotenoid concentrations, and also yolk weight, were calculated at baseline, and at week 6 using post hoc oneway ANOVA. For the within-group analysis of changes over time, repeated-measures ANOVA and paired $t$ tests could not be performed due to the hen housing system used, which allowed the hens within a specific group to mingle freely, so that eggs from individual hens in each group could not be identified at the different time points. Linear mixed models, with hen group as 'subject' variable, were also ruled out because, in this study, the treatment groups coincided with the hen groups. Therefore, differences over time (between baseline and week 6) for yolk weight and yolk carotenoids were investigated using independent-samples $t$ tests; statistically, these are more stringent tests than paired $t$ tests. The $5 \%$ level of significance was used throughout all analyses, without adjustment for multiple comparisons.

\section{Results}

\section{Hen feed supplement analysis}

The measured $v$. declared $\mathrm{L}, \mathrm{Z}$ and MZ carotenoid concentration (in $\mathrm{g} / \mathrm{kg}$ of active carotenoid in maize oil) is given in Table 1. The measured values were used to prepare the dosages given to the hens in order to achieve the uniform $140 \mathrm{mg} / \mathrm{kg}$ dosage across all eight intervention groups.

\section{Yolk carotenoid analysis, baseline and week 6}

Baseline. The baseline levels of L, Z, MZ and 13-cis-zeaxanthin (CisZ), presented as a mean value of four eggs of the same hen group, are given in Table 2. At baseline, there was no significant difference between the eight intervention groups in terms of $\mathrm{L}(P=0.446), \mathrm{Z}(P=$ $0 \cdot 352)$, CisZ $(P=0.075)$, total carotenoid $(P=0.091)$ or yolk weight $(P=0.634)$. Yolks in all groups at baseline were between DSM colour grades 12 and 14. MZ was not detected at baseline in any of the yolk samples tested.

Week 6. For each of the supplemented carotenoids L, Z and MZ, we compared week 6 with baseline using independent-samples $t$ tests; other approaches (e.g. paired 
Table 2. Baseline carotenoid levels and yolk weights for the eight hen intervention groups* (Mean values and standard deviations)

\begin{tabular}{|c|c|c|c|c|c|c|c|c|c|c|}
\hline \multirow[b]{2}{*}{ Group (n 4) } & \multicolumn{2}{|c|}{ L ( $\mu \mathrm{g} / \mathrm{yolk})$} & \multicolumn{2}{|c|}{ Z ( $\mu \mathrm{g} / \mathrm{yolk})$} & \multicolumn{2}{|c|}{ CisZ ( $\mu \mathrm{g} / \mathrm{yolk})$} & \multicolumn{2}{|c|}{ TC ( $\mu \mathrm{g} / \mathrm{yolk})$} & \multicolumn{2}{|c|}{ YW (g) } \\
\hline & Mean† & SD & Mean & SD & Mean & SD & Mean & SD & Mean & SD \\
\hline 1: Free Lł & 108.54 & 11.99 & 89.46 & 4.9 & 20.84 & 1.71 & 218.84 & 18.47 & 17.5 & 0.58 \\
\hline 2: L diacetate & 131.67 & 40.59 & 94.68 & $13 \cdot 15$ & 23.4 & 3.67 & 249.75 & $56 \cdot 92$ & $16 \cdot 5$ & 1.3 \\
\hline 3: Free Z & $132 \cdot 61$ & 37.68 & 91 & $20 \cdot 44$ & 21.04 & $4 \cdot 26$ & 244.64 & $60 \cdot 61$ & $16 \cdot 67$ & 1.12 \\
\hline 4: $Z$ diacetate & $108 \cdot 54$ & 11.07 & $87 \cdot 4$ & $16 \cdot 84$ & $21 \cdot 23$ & 4.6 & $217 \cdot 17$ & $30 \cdot 72$ & $16 \cdot 25$ & 0.96 \\
\hline 5: Free MZ & 117.49 & 4.29 & 94.3 & 6.4 & $22 \cdot 38$ & 1.31 & 234.18 & 11.57 & 16.5 & 0.58 \\
\hline 6: MZ diacetate & 107.53 & 1.42 & $76 \cdot 8$ & $10 \cdot 82$ & 18.86 & 3.41 & 203.19 & 15.63 & $15 \cdot 75$ & 1.5 \\
\hline 7: 1:1 mixture§ & $128 \cdot 8$ & $21 \cdot 32$ & $102 \cdot 11$ & 27.66 & 27.79 & 5.41 & 258.7 & 53.84 & $16 \cdot 75$ & 1.26 \\
\hline 8: 1:3 mixturell & 108.09 & $6 \cdot 11$ & 77.98 & 8.73 & $20 \cdot 2$ & $2 \cdot 42$ & $206 \cdot 27$ & $16 \cdot 35$ & 17 & 1.83 \\
\hline$P q$ & 0.446 & & 0.352 & & 0.075 & & 0.383 & & 0.656 & \\
\hline
\end{tabular}

L, lutein; Z, zeaxanthin; CisZ, 13-cis-zeaxanthin; TC, total carotenoid (sum of L, Z, MZ and CisZ); YW, yolk weight; MZ, meso-zeaxanthin.

${ }^{*}$ No MZ was identified in baseline yolk samples and was therefore not included in the Table.

$\dagger$ Mean refers to the mean carotenoid content of four eggs; each individual egg yolk sample was analysed without replication.

$\mp$ Free refers to the specified carotenoid in its free form.

$\$ 1: 1$ mixture refers to the $1: 1$ mixture of $L$ and $M Z$ diacetates.

II $1: 3$ mixture refers to the $1: 3$ mixture of $L$ and $M Z$ diacetates.

I Statistical significance between groups, tested using post hoc one-way ANOVA.

tests) were ruled out as explained above (Statistical analysis section). We obtained a significantly positive $(P<0 \cdot 001)$ time effect in all cases, suggesting strongly that the carotenoid concentrations in all L-, Z- and MZ-supplemented groups increased significantly over the duration of the study, albeit to varying extents. The specific carotenoids of interest and total carotenoid (defined as the sum of L, Z, MZ and CisZ) responses of all eight intervention groups are graphically presented in Fig. 2. The absolute value (in $\mu \mathrm{g} / \mathrm{yolk}$ ) achieved by each intervention group is given in Table 3. Of the interventions tested, the $\mathrm{Z}$ diacetate resulted in the maximum relative increase in yolk carotenoid concentration, represented by a total carotenoid concentration of 2528 (SD 237) $\mu \mathrm{g} /$ yolk at week 6 . Both mixture groups were effective responders, and, of interest, group 7 (the 1:1 mixture of L:MZ diacetate) achieved a L:MZ ratio (1:1) in the yolk samples. This can be seen in the chromatographic separation of a group 7 (1:1 mixture group) yolk extract presented in Fig. 3.

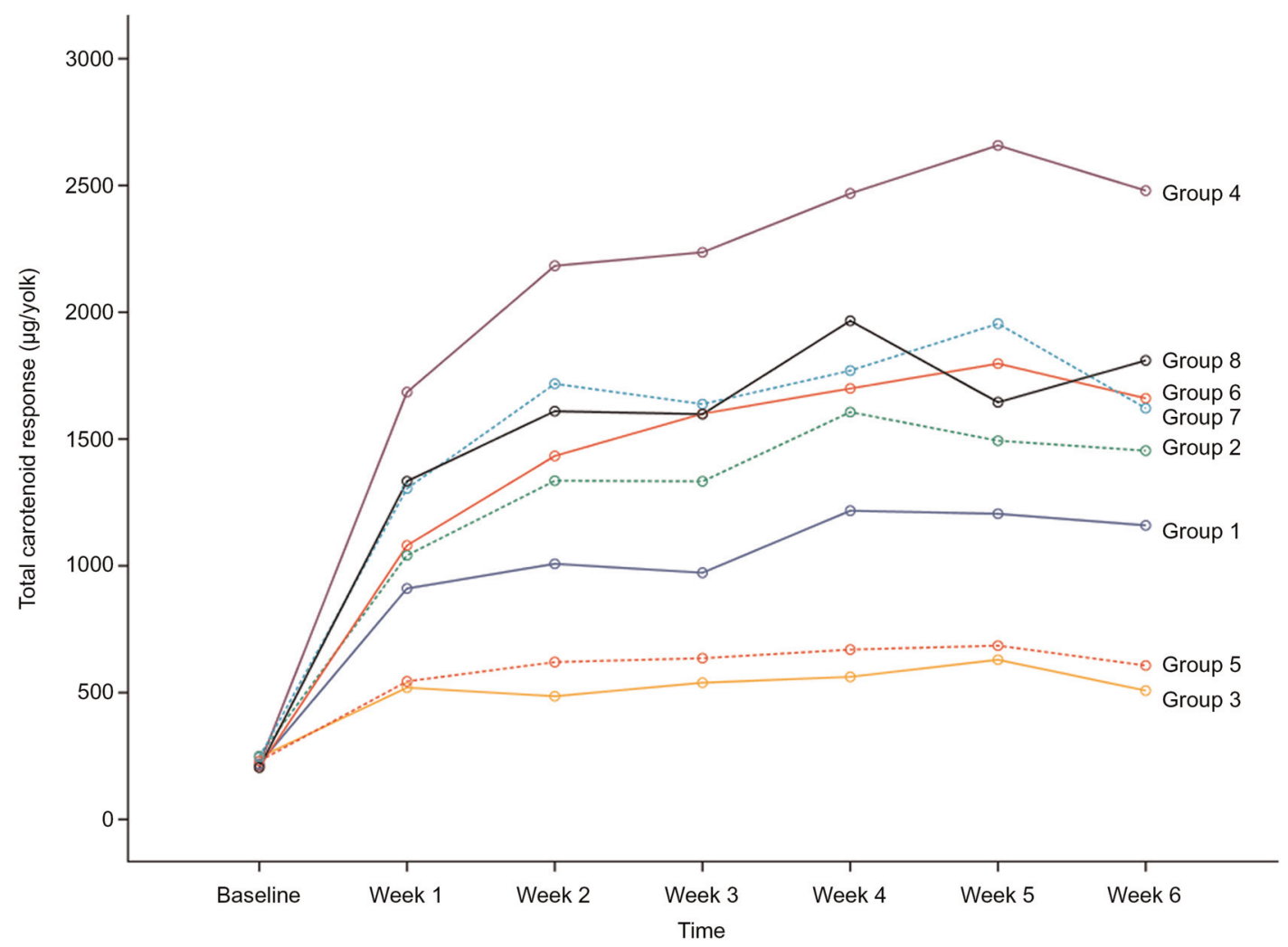

Fig. 2. Graphical presentations of the total carotenoid response in $\mu \mathrm{g} /$ yolk over the 6 -week study period. Group $1=$ free lutein $(L)$; group $2=L$ diacetate; group $3=$ free zeaxanthin (Z); group $4=Z$ diacetate; group 5 = free meso-zeaxanthin (MZ); group $6=\mathrm{MZ}$ diacetate; group $7=1: 1$ mixture of $L$ diacetate and $M Z$ diacetate; group $8=$ $1: 3$ mixture of $L$ diacetate and $M Z$ diacetate. Total carotenoid response is defined as the sum of $L, Z, M Z$ and $13-c i s-z e a x a n t h i n$ responses. 


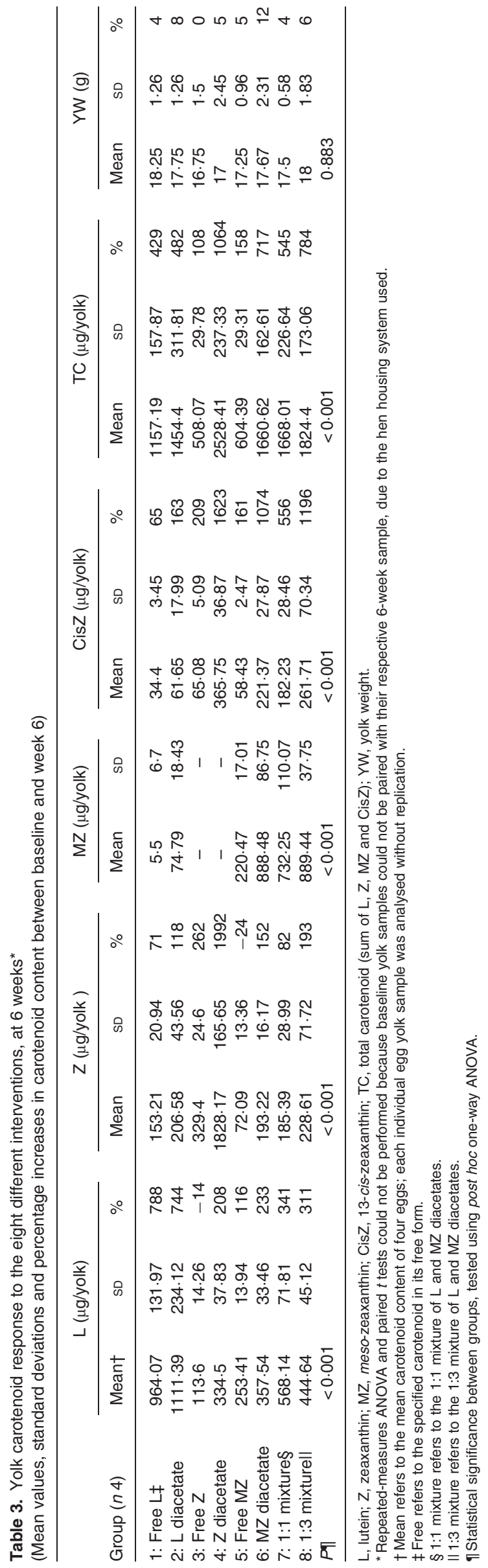

\section{Change in yolk weight and level of pigmentation}

Yolk weight did not demonstrate a significant increase over the 6-week study period for individual interventions. However, yolk pigmentation did demonstrate an increase during the study period. At baseline, none of the eggs was in colour category 15 (the highest possible category) but $83 \%$ of the eggs at baseline were in categories 13 or 14, spread comparably across the eight treatment groups. Eggs collected from weeks 3-6, however, showed substantial between-group differences in colour quality. For example, $94 \%$ of eggs from weeks 3-6 in group 4 ( $Z$ diacetate), $73 \%$ of eggs from group 7 (1:1 mixture of L:MZ diacetate) and $69 \%$ of eggs from group 2 (L diacetate) were in colour category 15 . In contrast, $0 \%$ of eggs from weeks 3-6 in groups 3 (free-form Z) and 5 (free-form MZ) were in colour category 15.

\section{Comparison of free $\mathrm{v}$. esterified supplementation}

As can be seen in Fig. 2 and in Table 3, the eggs of hens supplemented with the carotenoid diacetates (groups 2, 4 and 6) all demonstrated greater increases in carotenoid concentrations when compared with their respective free-form carotenoid counterparts. For $\mathrm{Z}$ and $\mathrm{MZ}$, the difference in observed responses was statistically significant (free $\mathrm{Z} v$. Z diacetate, $P<0 \cdot 001$; free MZ $v$. MZ diacetate, $P<0 \cdot 001)$, whereas this was not the case for $\mathrm{L}(P=0 \cdot 522)$.

\section{Additional carotenoid responses: 13-cis-zeaxanthin}

It was found that, where appreciable levels of $\mathrm{Z}$ and/or $\mathrm{MZ}$ were included in the feed, the levels of CisZ, tentatively identified using $\mathrm{UV} /$ visible spectroscopy, also increased. This isomer was also present in small amounts in all baseline yolk samples. Cis Z was found to correlate highly with total $\mathrm{Z}$ at baseline $\left(R^{2} 0 \cdot 781\right)$ and at week $6\left(R^{2} 0 \cdot 964\right)$. Given that this cis-isomer was not present in the original supplement, yet was present in baseline yolk samples, it seems likely that this cis-isomer is a result of natural metabolism of Z and/or MZ by the hen. Data with respect to CisZ at baseline and at week 6 are given in Tables 2 and 3, respectively.

\section{Discussion}

The Egg Xanthophyll Intervention Trial represents the first attempt to measure simultaneously the yolk carotenoid response to supplementation with $\mathrm{L}, \mathrm{Z}$ and $\mathrm{MZ}$ in hens. The main aims of this trial were to measure the egg yolk carotenoid response to hen supplementation with $\mathrm{L}, \mathrm{Z}$ and $\mathrm{MZ}$, and with combinations of these carotenoids, and also to compare the yolk carotenoid response to supplementation with the free and esterified forms of these xanthophylls.

All eight hen intervention groups responded significantly to supplementation in terms of the egg yolk carotenoid concentration. Of interest, in terms of the individual and total carotenoid responses, the $\mathrm{Z}$ diacetate intervention group resulted in significantly greater yolk response than the other intervention groups tested, achieving a Z content of 1828 (SD 165) $\mu \mathrm{g} /$ 


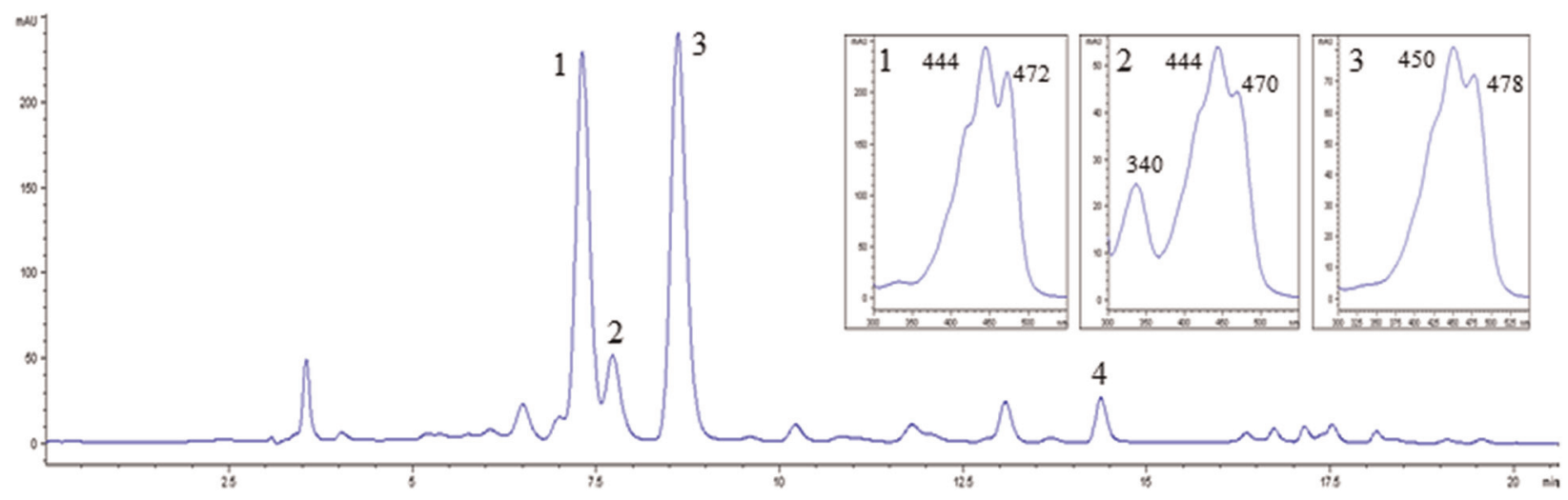

Fig. 3. Chromatograph and absorption spectra of a group 7 (1:1 mixture) yolk extract. Peak $1=$ lutein; peak $2=13$-cis-zeaxanthin; peak $3=$ total zeaxanthin (mixture of the zeaxanthin and meso-zeaxanthin isomers); peak $4=$ echinenone as the internal standard. The inset figures show the spectral details and the $\lambda_{\text {max }}$ of peaks 1,2 and 3 on the chromatogram. $\mathrm{AU}$, absorbance units.

yolk and a total carotenoid content of 2528 (SD 237) $\mu \mathrm{g} / \mathrm{yolk}$, equating to 1992 and $1064 \%$ increases, respectively. Although there is much more $\mathrm{L}$ in blood than $\mathrm{Z}$, comparative studies of xanthophyll absorption found $Z$ to be $30-47 \%$ more efficiently absorbed than L, although these data relate to supplementation with xanthophylls in their free form ${ }^{(32,33)}$.

Comparison of response to supplementation with the freeform carotenoids $v$. the diacetate carotenoids demonstrates that the esterified forms achieved a significantly greater response in the cases of $\mathrm{Z}$ and $\mathrm{MZ}$, but a comparable response in the case of $\mathrm{L}$, suggesting that the bioavailability of $\mathrm{Z}$ and $\mathrm{MZ}$ is greater in the diacetate form, while that of $\mathrm{L}$ is comparable between free and diacetate forms. With respect to colouration of enriched egg yolk, it should be appreciated that formal statistical tests of the 'group by colour' contingency table are problematic because of paucity of data (i.e. the conditions for the standard $\chi^{2}$ are not met, due to the small number of samples and the range of possible colour categories), and while there are additional statistical complications arising from eggs from the same hens being tested at different points in time, the results presented here do suggest that treatment with carotenoids in their diacetate form enhances yolk colour to a greater extent than treatment with these carotenoids in their free form.

Studies by Breithaupt et al. ${ }^{(34)}$, Wu et al. ${ }^{(30)}$ and Lai et al. ${ }^{(33)}$ report that hens supplemented with free-form $v$. esterified $\mathrm{L}$ result in a comparable hen serum carotenoid response and also yolk carotenoid response, suggesting similar bioavailabilities for the free and esterified forms of that carotenoid. However, hen supplementation studies by Galobart et al. ${ }^{(24)}$ and Hencken ${ }^{(35)}$ report greater bioavailability with free (saponified marigold extract) $v$. esterified (non-saponified marigold extract) in terms of yolk carotenoid deposition. The latter finding is consistent with the premise that hens need to first hydrolyse esterified carotenoids prior to absorption in the gastrointestinal tract, while free-form carotenoids can be absorbed in a way that precludes the need for hydrolysis $^{(36)}$. The requirement for hydrolysis could, in theory at least, have an adverse impact upon absorption efficiency, and therefore bioavailability, of esterified carotenoid supplements. However, the above studies have made their observations on the basis of supplementation with esterified marigold extract, which is an ester combination containing $95 \% \mathrm{~L}$ diester as lutein dipalmitates, myristate-palmitates and palmitatestearates $^{(37,38)}$, and not the singular (and lower-molecularweight) diacetate constituent used in this trial, which has demonstrated an equivalent or superior bioavailability to that of the free-form carotenoids in all cases.

The two mixture groups studied in this trial were 1:1 and 1:3 mixtures of L-MZ diacetate, and these mixtures achieved a statistically comparable total carotenoid response, though the 1:3 mixture of L-MZ diacetate did achieve a higher (but statistically comparable) total carotenoid content than the 1:1 mixture (1824 (SD 173) $\mu \mathrm{g} /$ yolk (784\% increase) and 1668 (SD 226) $\mu \mathrm{g} /$ yolk (545\% increase), respectively).

Another carotenoid isomer, which we believe to be CisZ, was identified in the yolk samples at baseline and was observed to increase in parallel with $\mathrm{Z}$ and/or $\mathrm{MZ}$ when the hens were given $\mathrm{Z}$ and/or $\mathrm{MZ}$ (either in diacetate or free-form) supplement preparations. This isomer was tentatively identified as CisZ based on its absorbance spectrum, which demonstrated an hypsochromic shift from the normal zeaxanthin spectrum, a large cis peak at $340 \mathrm{~nm}$, and lower spectral resolution commonly associated with cis-carotenoid spectra ${ }^{(39)}$. This isomer also appears in other studies in both supplemented and nonsupplemented egg yolks ${ }^{(40)}$, and appears to be present due to normal metabolic pathways associated with the hens' digestive and absorbance mechanisms.

This experiment had several limitations which are discussed below. First, as pointed out in our statistical methodology section, for the within-group analysis of changes over time, repeated-measures ANOVA and paired $t$ tests could not be performed due to the hen housing system used, which allowed the hens within a specific group to mingle freely, so that eggs from individual hens in each group could not be identified at the different time points. Significant efforts were made in this experiment to provide an environment safe and suitable to control the hens and many different feeding groups, but the inability of this experiment to cage hens individually and collect eggs from individual hens will have introduced variation into the study, as it is known that there are individual differences between birds that were not controlled for in this 
experiment. However, we are confident that the customisedbuilt barn for this study provided consistent environmental conditions for each intervention group studied. For example, the barn was newly built, well-sealed from the outside environment, and had no window (to limit unwanted dramatic temperature change). Another limitation of the present study was the omission of a control group during this experiment. However, we know from a follow-on study using the same experimental methodology that there is no significant change in egg yolk xanthophyll concentrations over time when hens are fed a standard diet (i.e. in a control group) (JM Nolan, KA Meagher, AN Howard, R Moran, DI Thurnham and S Beatty, unpublished results).

In conclusion, supplemental $\mathrm{L}, \mathrm{Z}$ or $\mathrm{MZ}$ added to the feed of hens results in egg yolks with significantly higher concentrations of the xanthophyll carotenoids when compared with unsupplemented (baseline) concentrations. Furthermore, the diacetate forms of $\mathrm{Z}$ and $\mathrm{MZ}$ yield greater responses, in terms of egg yolk concentrations of these carotenoids, than their respective free forms. These findings will inform attempts to develop a novel food designed to increase MP, and its constituent carotenoids in serum, and confer associated health and visual benefits.

\section{Acknowledgements}

This project was supported by the Howard Foundation (English Charity reg. no. 285822), Cambridge UK. We would like to acknowledge the hen farmers (Kevin McKenna and Colette McKenna) for supporting this egg experiment on their hen farm.

J.M.N. contributed to the design the trial. J.M.N was the project manager on the trial and helped with statistical analysis and data interpretation. J.M.N drafted the final manuscript. K.A.M. contributed to the design of the trial and carried out the experimental procedures, statistical analysis and data interpretation (as part of her post-graduate research study). K.A.M. prepared the initial draft of the manuscript. D.I.T. helped with data interpretation and statistical analysis, and helped to draft the manuscript. S.B. helped to the draft the manuscript and interpret the data. A.N.H. helped with the design of the trial and to draft the manuscript. R.M. contributed to the analytical HPLC work and drafting the paper. All authors have read and approved the final manuscript. J.M.N. is funded by the European Research Council (ERC) under the CREST project (code: 281096) and also holds a Howard Chair at Waterford Institute of Technology in Human Nutrition Research. J.M. N. and S.B. do consultancy work for nutraceutical companies as directors of Nutrasight Consultancy Ltd. D.I.T. is a consultant to the Howard Foundation and receives consulting fees for same. All other authors report no potential conflicts of interest.

\section{References}

1. Bone RA, Landrum JT, Friedes LM, et al. (1997) Distribution of lutein and zeaxanthin stereoisomers in the human retina. Exp Eye Res 64, 211-218.
2. Hirsch J \& Curcio CA (1989) The spatial resolution capacity of human foveal retina. Vision Res 29, 1095-1101.

3. Snodderly DM, Brown PK, Delori FC, et al. (1984) The macular pigment. I. Absorbance spectra, localization, and discrimination from other yellow pigments in primate retinas. Invest Opbthalmol Vis Sci 25, 660-673.

4. Khachik F, Beecher GR, Goli MB, et al. (1992) Separation and identification of carotenoids and their oxidation products in the extracts of human plasma. Anal Chem 64, 2111-2122.

5. Sabour-Pickett S, Nolan JM, Loughman J, et al. (2012) A review of the evidence germane to the putative protective role of the macular carotenoids for age-related macular degeneration. Mol Nutr Food Res 56, 270-286.

6. Sabour-Pickett S, Beatty S, Connolly E, et al. (2014) Supplementation with three different macular carotenoid formulations in patients with early age-related macular degeneration. Retina 34, 1757-1766.

7. Murray IJ, Makridaki M, van der Veen RL, et al. (2013) Lutein supplementation over a one-year period in early AMD might have a mild beneficial effect on visual acuity: the CLEAR study. Invest Ophthalmol Vis Sci 54, 1781-1788.

8. Weigert G, Kaya S, Pemp B, et al. (2011) Effects of lutein supplementation on macular pigment optical density and visual acuity in patients with age-related macular degeneration. Invest Ophthalmol Vis Sci 52, 8174-8178.

9. Loughman J, Nolan JM, Howard AN, et al. (2012) The impact of macular pigment augmentation on visual performance using different carotenoid formulations. Invest Ophthalmol Vis Sci 53, 7871-7880.

10. Craft NE, Haitema TB, Garnett KM, et al. (2004) Carotenoid, tocopherol, and retinol concentrations in elderly human brain. J Nutr Health Aging 8, 156-162.

11. Johnson EJ, Vishwanathan R, Johnson MA, et al. (2013) Relationship between serum and brain carotenoids, $\alpha$-tocopherol, and retinol concentrations and cognitive performance in the oldest old from the Georgia Centenarian Study. J Aging Res 2013, 951786.

12. Vishwanathan R, Iannaccone A, Scott TM, et al. (2014) Macular pigment optical density is related to cognitive function in older people. Age Ageing 43, 271-275.

13. Renzi LM, Dengler MJ, Puente A, et al. (2014) Relationships between macular pigment optical density and cognitive function in unimpaired and mildly cognitively impaired older adults. Neurobiol Aging 35, 1695-1699.

14. Goldberg EM, Ryland D, Gibson RA, et al. (2013) Designer laying hen diets to improve egg fatty acid profile and maintain sensory quality. Food Sci Nutr 1, 324-335.

15. Stergiadis S, Leifert C, Seal CJ, et al. (2014) Improving the fatty acid profile of winter milk from housed cows with contrasting feeding regimes by oilseed supplementation. Food Chem 164, 293-300.

16. Perry A, Rasmussen H \& Johnson EJ (2009) Xanthophyll (lutein, zeaxanthin) content of fruits, vegetables and corn and egg products. J Food Comp Anal 22, 9-15.

17. Maoka T, Arai A, Shimizu M, et al. (1986) The first isolation of enantiomeric and meso-zeaxanthin in nature. Comp Biochem Physiol B 83, 121-124.

18. Nolan JM, Beatty S, Meagher KA, et al. (2014) Verification of mesozeaxanthin in fish. J Food Process Technol 5, 335.

19. Rich GT, Bailey AL, Faulks RM, et al. (2003) Solubilization of carotenoids from carrot juice and spinach in lipid phases: I. Modeling the gastric lumen. Lipids 38, 933-945.

20. Yeum KJ \& Russell RM (2002) Carotenoid bioavailability and bioconversion. Annu Rev Nutr 22, 483-504.

21. Courraud J, Berger J, Cristol JP, et al. (2013) Stability and bioaccessibility of different forms of carotenoids and vitamin A during in vitro digestion. Food Chem 136, 871-877.

22. Handelman GJ, Nightingale ZD, Lichtenstein AH, et al. (1999) Lutein and zeaxanthin concentrations in plasma after dietary supplementation with egg yolk. Am J Clin Nutr 70, 247-251. 
23. Chung HY, Rasmussen HM \& Johnson EJ (2004) Lutein bioavailability is higher from lutein-enriched eggs than from supplements and spinach in men. J Nutr 134, 1887-1893.

24. Galobart J, Sala R, Rincón-Carruyo X, et al.(2014) Egg yolk color as affected by saponification of different natural pigmenting sources. J Appl Poult Res 13, 328-334.

25. Thurnham DI (2007) Macular zeaxanthins and lutein - a review of dietary sources and bioavailability and some relationships with macular pigment optical density and age-related macular disease. Nutr Res Rev 20, 163-179.

26. Wenzel AJ, Gerweck C, Barbato D, et al. (2006) A 12-wk egg intervention increases serum zeaxanthin and macular pigment optical density in women. J Nutr 136, 2568-2573.

27. Meagher KA, Thurnham DI, Beatty S, et al. (2013) Serum response to supplemental macular carotenoids in subjects with and without age-related macular degeneration. Br J Nutr 110, 289-300.

28. Thurnham DI, Nolan JM, Howard AN, et al. (2015) Macular response to supplementation with differing xanthophyll formulations in subjects with and without age-related macular degeneration. Graefes Arch Clin Exp Opbthalmol 253, 1231-1243.

29. Bowen PE, Herbst-Espinosa SM, Hussain EA, et al. (2002) Esterification does not impair lutein bioavailability in humans. J Nutr 132, 3668-3673.

30. Wu L, Huang X, Shi K, et al. (2009) Bioavailability comparison of free and esterified lutein for layer hens. Rev Bras Cienc Avic 11, 95-98.

31. Yeum KJ, Booth SL, Sadowski JA, et al. (1996) Human plasma carotenoid response to the ingestion of controlled diets high in fruits and vegetables. Am J Clin Nutr 64, 594-602.
32. Thurnham DI, Trémel A \& Howard AN (2008) A supplementation study in human subjects with a combination of meso-zeaxanthin, (3R,3'R)-zeaxanthin and (3R, 3'R, $\left.6^{\prime} \mathrm{R}\right)$-lutein. BrJ Nutr 100, 1307-1314.

33. Lai S-M, Gray IJ, Flegal CJ, et al. (1996) Deposition of carotenoids in eggs from hens fed diets containing saponified and unsaponified oleoresin paprika. J Sci Food Agric 72, 166-170.

34. Breithaupt DE, Weller P \& Grashorn MA (2003) Quantification of carotenoids in chicken plasma after feeding free or esterified lutein and capsanthin using high-performance liquid chromatography and liquid chromatography-mass spectrometry analysis. Poult Sci 82, 395-401.

35. Hencken H (1992) Chemical and physiological behavior of feed carotenoids and their effects on pigmentation. Poult Sci 71, 711-717.

36. Tyczkowski JK \& Hamilton PB (1986) Lutein as a model dihydroxycarotenoid for the study of pigmentation in chickens. Poult Sci 65, 1141-1145.

37. Rivas JD (1989) Reversed-phase high-performance liquid chromatographic separation of lutein and lutein fatty acid esters from marigold flower petal powder. J Chromatogr 464, 442-447.

38. Breithaupt DE, Wirt U \& Bamedi A (2002) Differentiation between lutein monoester regioisomers and detection of lutein diesters from marigold flowers (Tagetes erecta L.) and several fruits by liquid chromatography-mass spectrometry. I Agric Food Chem 50, 66-70.

39. Schieber A \& Carle R (2005) Occurrence of carotenoid cis-isomers in food: technological, analytical, and nutritional implications. Trends Food Sci Technol 16, 416-422.

40. Nimalaratne C, Lopes-Lutz D, Schieber A, et al. (2012) Effect of domestic cooking methods on egg yolk xanthophylls. J Agric Food Chem 60, 12547-12552. 